\title{
Morbidity profile of noncommunicable diseases among elderly in a city in North India
}

\author{
Gurmeet Kaur ${ }^{a}$, Rahul Bansal ${ }^{b}$, Tanu Anand ${ }^{a, *}$, Abhimanyu Kumar ${ }^{c}$, Jagmeet Singh ${ }^{\mathrm{d}}$ \\ a Department of Community Medicine, Hindu Rao Hospital And North Delhi Municipal Corporation Medical College, New Delhi, India, India \\ ${ }^{\mathrm{b}}$ Department of Community Medicine, Subharti Medical College, Meerut, India, India \\ ${ }^{\mathrm{c}}$ Central Institute of Orthopaedics, Vardhman Mahavir Medical College and Safdarjung Hospoital, New Delhi, India, India \\ d Centre for Laser Cosmetic Surgery, Jalandhar, India, India
}

\section{A R T I C L E I N F O}

\section{Article history:}

Received 10 November 2017

Received in revised form 12 December 2017

Accepted 14 December 2017

Available online 15 December 2017

\section{Keywords:}

Geriatric

Ageing

NCD risk factors

\begin{abstract}
A B S T R A C T
Background: Ageing is not an illness, but the elderly are vulnerable to slowly evolving chronic diseases. The difficulties faced by the elderly are uncountable leading to social and cultural differences in the present Indian society.

Objective: This study was conducted to assess the socio-demographic profile, lifestyle practices and morbidities of the elderly and their association, particularly with non-communicable diseases.

Methodology: A cross-sectional study was carried out in the field practice area of a medical college in a city in north part of India. A total of 225 elderly patients ( 60 years old and above) residing in urban area were interviewed using a pre-tested questionnaire through house-to-house visit.

Results: Out of the total, there were $51.1 \%$ females $(n=115), 99.1 \%$ Hindus $(n=223), 51.1 \%$ married $(n=115)$, $79.6 \%$ lived in joint families $(n=179)$ and $52.9 \%$ belonged to upper middle class $(n=119)$. Tobacco consumption was seen in $62.1 \%$ (smoking; $n=110$ ) and $19.7 \%$ (smokeless; $n=35$ ) elderly. About $18 \%$ $(n=32)$ were consuming alcohol. More than half of the study participants were not doing physical activity. Majority of the elderly in the study $(n=197 ; 87.6 \%)$ had one or more diagnosed diseases at the time of study. Morbidity was found associated with type of family, regular exercise, dietary habit, addiction user, duration of smoking, socio-economic status, alcohol consumption, smoking and tobacco chewing.

Conclusion: Many of the lifestyle practices such as tobacco use, alcohol consumption and physical inactivity were prevalent amongst elderly. Majority of them were suffering from more than one morbidity, which was found to be associated with their unhealthy lifestyle practices. There is a need to target interventions for inculcating healthy lifestyle practices amongst elderly.
\end{abstract}

(c) 2017 INDIACLEN. Published by Elsevier, a division of RELX India, Pvt. Ltd. All rights reserved.

\section{Background}

Every citizen holds prime importance in every country but geriatric (aged 60 years and above) ${ }^{1}$ are the most valuable asset for any country as their life long experience and wisdom contributes towards the progress of the nation. The independence, participation, care, self-fulfillment, and dignity of older persons has an ensured priority as per the United Nations. ${ }^{2}$

India with $8.2 \%$ of its population being more than 60 years old has acquired the level of an aging nation with growth of older Indian population in absolute number comparatively faster than the other regions of the world. It is projected that the elderly

\footnotetext{
* Corresponding author at: Department of Community Medicine, Hindu Rao Hospital And North Delhi Municipal Corporation Medical College, New Delhi, India. E-mail address: drtanu.anand@gmail.com (T. Anand).
}

population will be doubled by the year 2026 (173 million) in comparison with the year 2006 (83.6 million) in India. ${ }^{3}$

Aging is a naturally occuring universal process of all human beings. It includes changes in an individual's physical, psychological, and health-related capabilities, which are altering with time and its implications for the consequent changes in the individual's role in the economy and in the society. ${ }^{4}$ It is not an illness, but the elderly are vulnerable to slowly evolving chronic diseases. They present with mixed symptomatology due to decreased metabolic activities. The difficulties faced by the elderly are uncountable leading to social and cultural differences in the present Indian society. This brings in a greater responsibility on the health services in developing nations like India, where there is constant inadequacy in the present health infrastructure. ${ }^{5}$ In the view of all these facts, this study was conducted to study the socio- 
Table 1

Bivariate analysis of socio-demographic and lifestyle practices amongst elderly population of city in North India.

\begin{tabular}{|c|c|c|c|c|c|c|c|}
\hline Socio-demographic Profile & & Males N (\%) & Females N (\%) & Total N (\%) & OR & $95 \% \mathrm{CI}$ & $\mathrm{P}$ value \\
\hline \multirow[t]{2}{*}{ Religion } & Hindu & $110(100)$ & $113(98.3)$ & $223(99.1)$ & 0.88 & $0.83-0.92$ & 0.706 \\
\hline & Others & $0(0.0)$ & $2(1.7)$ & $2(0.9)$ & & & \\
\hline \multirow[t]{4}{*}{ Marital Status } & Married & $68(61.8)$ & $47(40.9)$ & $115(51.1)$ & 1.73 & $0.77-3.88$ & 0.181 \\
\hline & Divorced & $0(0.0)$ & $1(0.9)$ & $1(0.4)$ & & & \\
\hline & Widow/widower & $39(35.5)$ & $67(58.3)$ & $106(47.1)$ & & & \\
\hline & Unmarried & $3(2.7)$ & $0(0.0)$ & $3(1.3)$ & & & \\
\hline \multirow[t]{2}{*}{ Type of Family } & Joint & $81(73.6)$ & $98(85.2)$ & $179(79.6)$ & 4.31 & $1.88-9.89$ & $0.000^{*}$ \\
\hline & Nuclear & $29(26.4)$ & $17(14.8)$ & $46(20.4)$ & & & \\
\hline \multirow[t]{7}{*}{ Education } & Illiterate & $31(28.2)$ & $85(73.9)$ & $116(51.6)$ & 1.30 & $0.27-6.20$ & 0.741 \\
\hline & Primary school & $13(11.8)$ & $10(8.7)$ & $23(10.2)$ & & & \\
\hline & Middle School & $16(14.5)$ & $10(8.7)$ & $26(11.6)$ & & & \\
\hline & High School & $20(18.2)$ & $7(6.1)$ & $27(12.7)$ & & & \\
\hline & Intermediate & $18(16.4)$ & $2(1.7)$ & $20(8.9)$ & & & \\
\hline & Graduate/Postgraduate & $11(10.0)$ & $1(0.9)$ & $12(5.3)$ & & & \\
\hline & Professional & $1(0.9)$ & $0(0.0)$ & $1(0.4)$ & & & \\
\hline \multirow[t]{4}{*}{ Socioeconomic status } & Upper Class & $0(0.0)$ & $2(1.7)$ & $2(0.9)$ & 6.6 & $2.40-18.05$ & $0.000^{*}$ \\
\hline & Upper middle class & $67(60.9)$ & $52(45.2)$ & 119 (52.9) & & & \\
\hline & Lower middle class & $31(28.2)$ & $48(41.7)$ & $79(35.1)$ & & & \\
\hline & Upper lower & $12(10.9)$ & $13(11.3)$ & $25(11.1)$ & & & \\
\hline \multirow[t]{4}{*}{ Age } & $60-64$ & $22(20.0)$ & $31(26.9)$ & $53(23.6)$ & 0.46 & $0.20-1.04$ & 0.058 \\
\hline & $65-69$ & $24(21.8)$ & $30(26.1)$ & $54(24.0)$ & & & \\
\hline & $70-74$ & 35 (31.9) & $27(23.5)$ & $62(27.6)$ & & & \\
\hline & $>=80$ & $16(14.5)$ & $14(12.2)$ & $30(13.3)$ & & & \\
\hline \multirow[t]{4}{*}{ Sleep Duration } & $<4 \mathrm{~h}$ & $8(7.3)$ & $14(12.2)$ & $22(9.8)$ & 1.22 & $0.52-2.83$ & 0.650 \\
\hline & $4-<6 h$ & $23(20.9)$ & $36(31.3)$ & $59(26.2)$ & & & \\
\hline & $6-8 \mathrm{~h}$ & $62(56.4)$ & $49(42.6)$ & $111(49.3)$ & & & \\
\hline & $>8 \mathrm{~h}$ & $17(15.5)$ & $16(13.9)$ & $33(14.7)$ & & & \\
\hline \multirow[t]{2}{*}{ Involvement in Household work } & Yes/actively involved & $29(26.4)$ & $53(46.1)$ & $82(36.4)$ & 0.53 & $0.24-1.17$ & 0.111 \\
\hline & No/Not actively involved & $81(73.6)$ & $62(53.9)$ & $143(63.6)$ & & & \\
\hline \multirow[t]{2}{*}{ Dietary Habits } & Vegetarian & $95(86.4)$ & $105(91.3)$ & $200(88.9)$ & 0.86 & $0.81-0.91$ & $0.046^{*}$ \\
\hline & Non-vegetarian & $15(13.6)$ & $10(8.7)$ & $25(11.1)$ & & & \\
\hline \multirow[t]{2}{*}{ Exercises } & Yes & $53(48.2)$ & $40(34.7)$ & $93(41.3)$ & 1.27 & $1.16-1.38$ & $0.000^{*}$ \\
\hline & No & $57(51.8)$ & $75(65.2)$ & $132(58.6)$ & & & \\
\hline \multirow[t]{2}{*}{ Type of exercise } & Walking & $43(81.1)$ & $35(87.5)$ & $78(83.8)$ & 0.92 & $0.87-0.98$ & 0.283 \\
\hline & Yoga & $10(18.8)$ & $5(12.5)$ & $15(16.1)$ & & & \\
\hline \multirow[t]{2}{*}{ Frequency of exercise } & Daily & $43(81.1)$ & $27(67.5)$ & $70(75.2)$ & 0.59 & $0.06-5.34$ & 0.636 \\
\hline & Once or twice a week & $10(18.8)$ & $13(32.5)$ & $23(24.7)$ & & & \\
\hline \multirow[t]{2}{*}{ Duration of exercise } & Less than 30 mins & $22(41.5)$ & $22(55)$ & $44(47.3)$ & 0.03 & $0.05-0.71$ & 0.478 \\
\hline & More than 30 mins & $31(59.4)$ & $18(45)$ & $49(52.6)$ & & & \\
\hline \multirow[t]{2}{*}{ Addictions } & Yes & $86(78.2)$ & $40(34.7)$ & $126(56)$ & 3.66 & $1.54-8.71$ & $0.002^{*}$ \\
\hline & No & $24(21.8)$ & $75(65.2)$ & $99(44)$ & & & \\
\hline \multirow[t]{3}{*}{ Type of addiction } & Smoking & $55(60.4)$ & $55(63.9)$ & $110(62.1)$ & 1.32 & $1.19-1.47$ & $0.000^{*}$ \\
\hline & Alcohol & $12(13.1)$ & $20(23.2)$ & $32(18)$ & 1.17 & $1.10-1.24$ & $0.021^{*}$ \\
\hline & Smokeless tobacco & $24(26.3)$ & $11(12.7)$ & $35(19.7)$ & 1.17 & $1.11-1.24$ & $0.015^{*}$ \\
\hline \multirow[t]{3}{*}{ Duration of addiction ( $>30$ Years) } & Smoking & $55(60.4)$ & $55(63.9)$ & $110(62.1)$ & 19.76 & $2.19-17.83$ & $0.000^{*}$ \\
\hline & Alcohol & $12(13.1)$ & $20(23.2)$ & $32(18)$ & 0.92 & $0.79-1.08$ & 0.219 \\
\hline & Smokeless Tobacco & $24(26.3)$ & $11(12.7)$ & $35(19.7)$ & 3.80 & $0.59-24.46$ & 0.143 \\
\hline \multirow[t]{3}{*}{ Trend of addiction of smokers } & Ever user & $16(14.5)$ & $11(9.6)$ & $27(12.0)$ & 3.66 & $1.54-8.71$ & $0.002^{*}$ \\
\hline & Current user & $70(63.6)$ & $29(25.2)$ & $99(44)$ & & & \\
\hline & Never user & $24(21.8)$ & $75(65.2)$ & $99(44)$ & & & \\
\hline \multirow[t]{2}{*}{ Quantity of Bidi smoked per day } & 2 bundles ( 12 bidi) & $36(65.4)$ & $48(87.2)$ & $84(76.3)$ & 0.86 & $0.82-0.91$ & 0.106 \\
\hline & 4 bundles ( 24 bidi) & $19(34.5)$ & $7(12.7)$ & $26(23.6)$ & & & \\
\hline
\end{tabular}

Note: \% denote column percentages; ${ }^{*} \mathrm{p}<0.05$.

Titles and variable has been marked as bold. 
demographic profile and morbidities of the elderly particularly the non-communicable diseases of insidious onset.

\section{Methodology}

\subsection{Study setting and study participants}

This was a community based cross-sectional study carried out among elderly in urban population of catchment area of urban health and training center (UHTC) of a Medical college in a city in North India. The district has a total population of 34 , which includes 18 , males and 16 , females. Population density is 1347 persons per square kilometer. ${ }^{6}$

Study period: The study was conducted between 1 st Jan 2016 to 31 st Dec 2016.

\subsection{Sampling and sample size}

The sampling universe was 2112 registered families residing in the study area from at least past 1 year and the sampling unit was a family. The morbidity in the pilot study done on similar population was found to be $87.7 \% .^{7}$ Using the formula: $n=4 \mathrm{pq} / \mathrm{L} 2$, where, $\mathrm{n}=$ required sample size $\mathrm{p}=$ prevalence of morbidity (for this study) $=87.7, q=100-p=100-87.7=12.3, L=5 \%$ of $p=4.38$, Sample Size $(\mathrm{n})$ was calculated to be; $4 \times 87.7 \times 12.3 / 4.38 \times 4.38=224.9$ i.e. $\approx 225$. In the pilot survey, it was also found that average number of elderly in each family was 1 , so number of families required to recruit the required number of subjects was 225 . According to systematic random sampling, the sampling interval was $2112 / 225=9.38$. For the collection of data, first family was selected randomly by lottery method then every 9 th family was taken and the elderly $\geq 60$ years of selected family were included in the study till the required number of subjects were interviewed. If any adult $\geq 60$ years was not found in a family or selected house was found locked at the time of interview then adjacent family was visited.

\subsection{Study tool}

A pretested, self-administered, structured questionnaire was used for data collection. For illiterate participants, the investigator filled the questionnaire. It included items to record socio-demographic characteristics, assess the presence of due to noncommunicable diseases and lifestyle practices associated with them, among elderly. The questionnaire was developed based on literature review and was assessed for suitability, relevance and accuracy in the Indian context. It was pretested in the Hindi language among 50 elderly and was suitably modified by removing 10 questions which were not relevant to objective of study and study settings. Internal consistencies of the items on Morbidity profile of non communicable diseases among elderly were obtained through Cronbach's alpha coefficient (0.90). The questionnaire was divided into 3 sections. The first section consisted of 11 questions pertaining to the socio demographic profile of elderly. The second section consisted of lifestyle practices including hours of sleep, involvement in household work, involvement in part time job, regular exercise patterns, dietary habits and addiction habits including type (smoking, alcohol and smokeless tobacco) and duration of addiction. Among the addiction practices for smoking, agent(cigarette or bidi ${ }^{\mathrm{e}}$ ) and quantity (in number) was also assessed. ${ }^{8}$ The third section

\footnotetext{
e Bidis are small thin handrolled cigarettes which comprise of tobacco wrapped in a tendu or temburni leaf (plants native to Asia) and may be secured with a colorful string at one or both ends. These contain higher concerntrations of nicotine, tar and carbon monoxide than conventional cigarettes sold in United states and other countries.
}

consisted of questions to assess morbidities among elderly. Morbidity was examined using a checklist including 10 broad diseases and a residual category called "other diseases". The selfreported disease history was confirmed by reviewing medical records and medications, showing that the agreement between selfreports and medical records was fair to excellent (75-97\%). Cured morbidities were excluded to assess the prevalence of current morbidities.

\subsection{Survey procedure}

A single interviewer collected information regarding the population through house-to-house visit. Interview schedule consisted of a structured questionnaire and took roughly 40 to $45 \mathrm{~min}$ to complete, followed by a complete physical examination to rule out other co- morbidities.

\subsection{Analysis}

Data were entered in Microsoft Excel and analyzed in SPSS version 17. Findings were presented as group proportions, and difference in proportions for a given factor was assessed by the Chisquare test. A $P$ value cut off for statistical significance was set at 0.05 . Factors which were significantly associated $(P<0.05)$ with stress due to physical environment and job requirements in univariate analysis, were further analyzed using Binomial Logistic regression analysis. Odds Ratios (ORs) were calculated indicating the relative odds of occurrence of non-communicable diseases among elderly.

\subsection{Ethical issues}

All elderly who participated in the study were informed about the purpose of the study and full free and voluntary written consent was taken before their inclusion. Each participant was free to withdraw from the study at any point in time and was ensured confidentiality of the responses. The study was approved by the institutional ethics committee of the medical college.

\section{Result}

Out of 225 participants, (51.1\%) were females and (48.9\%) were males. Mean age of the study population was 70.6 years Most of elderly subjects were from 70 to 74 years age group, comprising (27.6\%) of the study population. The entire study population were predominantly Hindu by religion (99.1\%) and (51.1\%) were married. Majority of the population (79.6\%) lived in joint families. Almost half of the study population were illiterate $(51.6 \%$ ) of which $73.9 \%$ were males and $28.2 \%$ were females. Nearly half of the elderly (52.9\%) belonged to upper middle socio economic class according to Modified Kuppuswamy classification. (Table 1) Majority were vegetarians (88.9\%) and almost half (49.3\%) of the elderly population slept for duration of 6-8 h. More than half of the population (63.6\%) were not involved in any type of household work and $58.6 \%$ did not perform any form of exercise. (Table 1 )

Addiction was prevalent in more than half (56\%) of the elderly population from past 30 years. Majority $(62.1 \%)$ of them smoked bidi, of which $76.3 \%$ smoked 2 bundles ( 12 bidi) and $23.6 \%$ smoked 4 bundles ( 24 bidi) per day. Alcohol consumption was prevalent among (18\%) while the rest (19.7\%) were addicted to smokeless tobacco.

Majority of the elderly in the study (87.6\%) had one or more diagnosed diseases at the time of study. (Table 2) Maximum number of diseased states was found in 70 to 74 years age group (75.8\%).The total number of morbidities found in the study population was 756 and the number of morbidities per person 
Table 2

Presence of morbidity in the study population.

\begin{tabular}{|c|c|c|c|c|c|c|}
\hline & \multicolumn{4}{|c|}{ Morbidity } & \multicolumn{2}{|c|}{ Total } \\
\hline & \multicolumn{2}{|c|}{ Present } & \multicolumn{2}{|c|}{ Absent } & \multirow[b]{2}{*}{$\mathrm{N}$} & \multirow[b]{2}{*}{$\%$} \\
\hline & $\mathrm{N}$ & $\%$ & $\mathrm{~N}$ & $\%$ & & \\
\hline Males & 94 & 85.4 & 16 & 14.5 & 110 & 100 \\
\hline Females & 103 & 89.5 & 12 & 10.4 & 115 & 100 \\
\hline Total & 197 & 87.6 & 28 & 12.4 & 225 & 100 \\
\hline
\end{tabular}

Table 3

Age-wise distribution of study population as per number of morbidities.

\begin{tabular}{|c|c|c|c|c|c|c|c|c|c|c|}
\hline \multirow[t]{3}{*}{ Age (in years) } & \multicolumn{8}{|c|}{ Number of Morbidities } & \multicolumn{2}{|c|}{ Total } \\
\hline & \multicolumn{2}{|c|}{ Nil } & \multicolumn{2}{|c|}{1} & \multicolumn{2}{|c|}{2} & \multicolumn{2}{|c|}{$>2$} & \multirow[b]{2}{*}{$\mathrm{N}$} & \multirow[b]{2}{*}{$\%$} \\
\hline & $\mathrm{N}$ & $\%$ & $\mathrm{~N}$ & $\%$ & $\mathrm{~N}$ & $\%$ & $\mathrm{~N}$ & $\%$ & & \\
\hline $60-64$ & 0 & 0.0 & 7 & 13.2 & 9 & 17.0 & 37 & 69.8 & 53 & 100 \\
\hline $65-69$ & 3 & 5.5 & 7 & 13.0 & 10 & 18.5 & 34 & 63.0 & 54 & 100 \\
\hline $70-74$ & 1 & 1.6 & 4 & 6.5 & 10 & 16.1 & 47 & 75.8 & 62 & 100 \\
\hline $75-79$ & 0 & 0.0 & 2 & 7.7 & 5 & 19.2 & 19 & 73.1 & 26 & 100 \\
\hline$\geq 80$ & 0 & 0.0 & 4 & 13.3 & 5 & 16.7 & 21 & 70.0 & 30 & 100 \\
\hline Total & 4 & 1.8 & 24 & 10.7 & 39 & 17.3 & 158 & 70.2 & 225 & 100 \\
\hline
\end{tabular}

was 3.36. Morbidity rate was higher among elderly females 435 (3.8 morbidities per female elderly) than among elderly males 321 (2.9 morbidities per male elderly). (Table 3)

Among the elderly population, maximum were the ocular problems (78.7\%) followed by musculoskeletal disorders (71.6\%), hypertension (52.4\%), respiratory diseases (51.1\%), gastro-intestinal (36.9\%), coronary artery diseases (19.6\%) and diabetes mellitus (11.6\%). Other diseases included hearing loss (7.1\%), urinary incontinence $(7.1 \%)$, prolapse $(0.9 \%)$ and renal calculi $(0.4 \%)$. The elderly women had more ocular problems (81.7\%), musculoskeletal disorders (83.5\%), hypertension (67\%), coronary artery disease (21.7\%), diabetes mellitus (12.2\%), acid peptic disease (37.4\%), gallstones (6.1\%), hemorrhoids (1.7\%) and hearing loss $(9.6 \%)$ has compared to males.

On Bivariate analysis (Table 1 ) possible factors responsible for morbidity among study population were type of family $\mathrm{OR}=4.307$, $95 \% \mathrm{CI}=1.875-9.83$, p value $<0.001$, regular exercise $\mathrm{OR}=1.267,95 \%$ $\mathrm{CI}=1.160-1.383, \mathrm{p}$ value $<0.001$, dietary habit $(\mathrm{OR}=0.860,95 \%$ $\mathrm{CI}=0.813-0.909, \mathrm{p}$ value $=0.002)$, addiction user $(\mathrm{OR}=3.656,95 \%$ $\mathrm{CI}=1.535-8.708$, $\mathrm{p}$ value $=0.002$ ), duration of smoking $\mathrm{OR}=19.762$, $95 \% \mathrm{CI}=2.190-178.309, \mathrm{p}$ value $<0.001$,Socio-economic status $\mathrm{OR}=6.588,95 \% \mathrm{CI}=2.404-18.049$, p value $<0.001$,Alcohol consumption $(\mathrm{OR}=1.170,95 \% \mathrm{CI}=1.104-1.240$, $\mathrm{p}$ value $=0.021)$, smoking $\mathrm{OR}=1.322,95 \% \mathrm{CI}=1.192-1.466, \mathrm{p}$ value $<0.001$ and tobacco chewing $(\mathrm{OR}=1.73,95 \% \mathrm{CI}=1.106-1.244$, $\mathrm{p}$ value $=0.015)$

\section{Discussion}

The prevalence of morbidity among elderly population in this study was $87.6 \%$ which was similar to those reported in other studies. ${ }^{8-14}$ Two previous studies done in the United States, documented that the prevalence of morbidity was $87.6 \%$ and $82.0 \%$ respectively. ${ }^{10,12}$ Similarly the prevalence of morbidity was $86.7 \%$ in a community dwelling of Jewish group in Israel. ${ }^{10}$ The prevalence of morbidity among non-institutionalized older people in Spain was much higher, which was $95.3 \%{ }^{15}$ and $88.9 \%$ in elderly residents of Northern India. The differences in the prevalence may be attributable to differences in the racial and ethnic origins of the study populations and prevailing socio-demographic differences among them but our study findings were found consistent with the other Indian and Israeli studies which included subjects aged 60 years and over and those aged 75-94 years, respectively Our observations on age wise morbidity, were found consistent with study of Srivastava et $\mathrm{al}^{5}$ who observed that in urban Meerut nearly $60 \%$ were belonging to $60-69$ years age group and 33\% belonged to 70-79 years age group. Similar observations were made in other studies conducted in Meerut city ${ }^{6}$ as $62.4 \%$ and $30.3 \%$. In our study, females outnumbered males that is similar to studies conducted in various parts of India including Meerut, Ahmedabad and Patiala. ${ }^{5,6,15,16,17}$ Out of 225 elderly subjects, 106 (47.1\%) were widows/widowers of which widows were $63.2 \%$ and widowers were $36.8 \%$. The observation was similar to Khokhar et al ${ }^{18}$ and Niranjan et al. ${ }^{19}$

As elderly women were unemployed, widow, engaged in less exercise, smoking and other addiction practices, it could probably lead to poorer health status of elderly women in this study. Alternatively, the women may have been more interested in their own health and, consequently, may have indicated the presence of more disease conditions than did the men. Therefore, differences between men and women in the level of awareness and concern about their personal health could have affected their answers to the questions about current morbidity.

It was observed that illiteracy was high among the elderly with majority of elderly females being illiterate Other authors too noted a high illiteracy as well ${ }^{19,20,21,22}$. In this study, we found that lower level of education was associated with increased morbidity due to over reporting and improper management of chronology of diagnosed disease states. ${ }^{23}$ Addiction was more common among elderly males (78.2\%) as compared to elderly females (34.7\%). Smoking was found to be the most common addiction and was prevalent in $60.4 \%$ of the study population. which was similar to Khokhar et al ${ }^{18}$.

Life style-related diseases including ocular problems, musculoskeletal disorders, hypertension, respiratory diseases, and gastrointestinal diseases were the most common among these morbidities. Furthermore women had a greater number of morbidities than men,which was supported by Niranjan et al. ${ }^{19}$ and Padda et $\mathrm{al}^{24}$ Similar observations were found in Dey et al ${ }^{25}$, Khan et $\mathrm{al}^{26}$ and Nirankar et al. $^{6}$ Ocular problems were the most prevalent morbidity in our study affecting $78.7 \%$ of the study population. Here also, elderly females were more commonly affected than elderly males. Many authors have reported ocular problems, as the most prevalent morbidity 9,18,27,28,29,30. The second most common morbidity in our study was musculoskeletal disorders affecting $71.6 \%$ of the study population. Of which $83.5 \%$ were elderly females as compared to elderly males (59.1\%)and it was found significant with sex. Many authors have reported a high prevalence rate including Singh et al (61.5\%), Dey et al(35.3\%) and Khokhar et al $(60.1 \%)^{11,18,19,30}$ In our study, $52.4 \%$ of the population was suffering from hypertension which was more among females comprising $34.2 \%$ of the study population as compared to elderly males (18.2\%) which was found significant with sex. Our findings are in agreement with those reported by other authors Banker et al (54.2\%), Lena et al (59.1) and Prakash et al (48\%) $)^{16,6,18,20,21,25,27,31,32}$. Half of our study population was suffering from respiratory problems which was supported by Joshi et al ${ }^{9}$, Prakash et al ${ }^{27}$, Kishore et $\mathrm{al}^{33}$, Mohapatra et $\mathrm{al}^{34}$ and Ashok et al ${ }^{28}$ who observed similar prevalence. It was significantly higher among more than 80 years age group (60\%), having addiction and those who slept for less than $4 \mathrm{~h}$ Coronary artery disease was prevalent in $19.6 \%$ of the study population in the present study. Other authors reported similar prevalence as well which included Dey et al ${ }^{25}(18.9 \%)$, Srinivasan et $\mathrm{al}^{35}$ (27.9\%) and Kakkar et $\mathrm{al}^{36}(26.1 \%)$. Here also, the prevalence was more among females $(21.7 \%)$ as compared to males 
(17.3\%) Diabetes was prevalent in $11.6 \%$ of the study population which is similar to Bhatt et al ${ }^{31}(10.6 \%)$, Bhatia et al ${ }^{20}(11.9 \%)$ and Mohapatra et al $^{34}$ (7.9\%).Diabetes was found to be most prevalent in 75to 79 years age group and it was found to be statistically significant ( $p$-value $<0.05$ ). This current data are also relatively consistent with those in the study of an elderly cohort in Israel. ${ }^{10}$ In the study from Northern India, however, anemia and dental problems were reported to be the most prevalent diseases based on provisional diagnoses made after general physical examinations of the subjects. ${ }^{9}$ Hypertension, chronic obstructive airway disease, cataracts, osteoarthritis and only $5 \%$ of the subjects in that study had diabetes mellitus. In the study from Spain, osteoarthritis and related diseases were found to be the most prevalent morbidities, followed by vision impairment and hypertension. ${ }^{14}$ Again, the data in these studies are not entirely comparable owing to many differences in the conditions of the four studies.

It was found that progressive ageing was not significantly related to morbidity among the elderly, although old age is usually accompanied by a decline in physical fitness and increasing experience of body aches and pains. ${ }^{9}$ Therefore, it was concluded that most of the major chronic diseases in the current sample were established or diagnosed before the age of 60 and that thereafter a large proportion of the subjects had chronic diseases. After adjusting for socio-demographic variables, chronic disease was strongly associated with lifestyle and addiction practices. Multiple studies had demonstrated that lifestyle practices and addiction practices are a good predictor of mortality and functional ability, even after controlling for objective measurements of medical morbidity (for example, laboratory tests or physician reports). $37,38,39,40,41,42$ In this regard, it was reported that lifestyle and addiction practices are multifaceted, nuanced indicator of underlying health status that incorporates different dimensions of health (including physical disability and functional limitations), severity of any conditions, and comorbidity. ${ }^{43}$

The present study has several limitations that must be addressed in future studies. First, because the sample was drawn from one limited geographic area within the district, the results cannot properly be generalized to the national population. Second, because of the cross-sectional design, this study was unable to determine whether the various factors that showed correlations with morbidity in the elderly are antecedent to or consequences of morbidity. To resolve this question, a longitudinal follow up study using this cohort is currently being conducted. Third, geriatric epidemiologists are concerned that misreporting on self-assessments may increase with age and may vary greatly depending on the disease considered. More over, because morbidity was investigated using a questionnaire and the subjects were instructed to answer 'yes' only for diagnosed diseases, any unexpressed or undiagnosed diseases were not investigated. Nevertheless, the present study also has an advantage, which was based on a large, stratified, random sample of the elderly in India.

\subsection{Conclusion and recommendations}

This study has emphasized on the fact that the elderly suffered from multiple morbidities, which are often attributed to aging and more so in females. Many of the lifestyle practices such as tobacco use, alcohol consumption and physical inactivity were prevalent amongst elderly. The presence of morbidity was significantly found to be associated with unhealthy lifestyle practices. There is a need to target interventions for inculcating healthy lifestyle practices amongst elderly, which are very essential for prevention and control of non-communicable diseases amongst them.

\section{References}

1. Elango S. A study of health and health related social problems in geriatric population in a rural area of Tamil Nadu. Indian J Public Health. 1998;42(1):712.

2. World Health Organization. United Nations Principles for Older Person. Geneva, Switzerland: WHO; 1999.

3. National Institute of Social Defense. Age Care in India: National Initiative on Care for Elderly. India: NISD, Ministry of Social Justice and Empowerment, Government of India; 2008.

4. Rajan SI, Mishra US, Sharma PS. India's Elderly Burden or Challenge? New Delhi, India: Sage Publication; 1999.

5. Srivastava K, Parul S, Gupta SC, Kaushal SK, Chaturvedi M. Graying of the Nation: A Curse or Boon?Graying of the nation: a curse or boon?. J Gerontol Geriat Res. 2012;1:11510.4172/2167-7182.1000115.

6. Nirankar. A Socio- Medical Profile of the Elderly People in Urban Area of Meerut with Special Reference to Availability and Utilization of Geriatric Welfare Services. Meerut, India: C.C.S. University; 2005.

7. Shankar R, Tondon J, Gambhir IS. Tripathi CB: health status of elderly population in rural area of Varanasi district. Indian J Public Health. 2007;51 (1):56-58

8. https://www.cdc.gov/tobacco/data_statistics/fact_sheets/tobacco_industry/ bidis_kreteks/index.htm. [Accessed 24 th June 2017].

9. Joshi K, Kumar R, Avasthi A. Morbidity profile and its relationship with disability and psychological distress among elderly people in Northern India. Int J Epidemiol. 2003;32:978-987.

10. Fuchs $Z$, Blumstein $T$, Novikov I, et al. Morbidity, comorbidity, and their association with disability among community-dwelling oldest-old inIsrael. J Gerontol A Biol Sci Med Sci. 1998;53:M447-M455.

11. Shah B, Prabhakar AK. Chronic morbidity profile among elderly. Indian J Med Res. 1997; 106:265-272.

12. Hoffman C, Rice D, Sung HY. Persons with chronic conditions. Their prevalence and costs. JAMA. 1996;276:1473-1479.

13. Wolff JL, Starfield B, Anderson G. Prevalence, expenditures, and complications of multiple chronic conditions in the elderly. Arch Intern Med. 2002;162:22692276.

14. Valderrama-Gama E, Damian J, Ruigomez A, Martin-Moreno JM. Chronic disease, functional status, and self-ascribed causes of disabilities among noninstitutionalized older people in Spain. J Gerontol A Biol Sci Med Sci. 2002;57:M716-M721.

15. Goel PK, Garg SK, Singh JV, Bhatnagar M, Chopra H, Bajpai SK. Unmet needs of the elderly in a rural population of meerut. Indian J of Community Med. 2003;28 (4):165-166.

16. Banker K, Prajapati B, Kedia G. Study of health profile of residents of geriatric home in Ahmedabad district. Nat J Commun Med. 2011;2(3):378-382.

17. Singh N, Singh SK, Yadav A, Suman SK, Kumar S, Singh JV. Community based study of the morbidity profile among elderly people in a rural area of patiala district. J Adv Res Biol Sci. 2012:4(2):156-161.

18. Khokhar A, Mehra M. Life style and morbidity profile of geriatric population in an urban community of delhi. Indian J Med Sci. 2001;55:609-615.

19. Niranjan GV, Vasundhra MK. A study of health status of aged in slums of urban field practice area, Bangalore. Indian J Commun Med. 1996;19(1-4):37-40.

20. Bhatia SPS, Swami HM, Thakur JS, Bhatia V. A study of health problems and loneliness among the elderly in Chandigarh. Indian J Commun Med. 2007;32 (4):255-258.

21. Lena A, Ashok K, Padma M, Kamath V, Kamath A. Health and social problems of the elderly: a cross-sectional study in udupitaluka, karnataka. Indian J Commun Med. 2009;34(2):131-134.

22. Bharati DR, Pal R, Rekha R, Yamuna TV, Kar S, Radjou AN. Ageing in puducherry, south India: an overview of morbidity profile. J Pharm Bio Allied Sci. 2011;3:537-542.

23. Gazmararian JA, Williams MV, Peel J, Baker DW. Health literacy and knowledge of chronic disease. Patient Educ Couns. 2003;51:267-275.

24. Padda AS, Mohan V, Singh J, Deepti SS, Singh G, Dhillon HS. Health profile of aged persons in urban \& rural field practice areas of medical college, Amritsar. Indian J Commun Med. 1998;23(Apr-Jun 2):72-76.

25. Dey AB, Soneja S, Nagarkar KM, Jhingan HP. Evaluation of the health and functional Status of older Indians as a prelude to the development of a health program. Nat Med J India. 2001;14:135-138.

26. Khan Mohd Y, Al-Fifi SH. Health profile of the aged population in urban aligarh: India. Med J Cairo Univ. 2010;78(1):369-374.

27. Prakash R, Choudhary SK, Singh US. A study of morbidity pattern among geriatric population in an urban area of udaipur rajasthan. Indian J Commun Med. 2004;29(1):35

28. Kumar AT, Sowmiya KR, Radhika G. Morbidity pattern among the elderly people living in a southern rural India - a cross sectional study. Nat. J Res Com Med. 2012;1(1):01-60.

29. Chacko A, Joseph A. Health problems of the elderly in rural south India. Indian J Commun Med. 1990;15:70-73.

30. Shraddha K, Prashantha B, Prakash B. Study on morbidity pattern among elderly in urban population of mysore, karnataka, India. Int J Med Biomed Res. 2012;1(3):215-223.

31. Bhatt R, Gadhvi MS, Sonaliya KN, Solanki A, Nayak H. An epidemiological study of the morbidity pattern among the elderly population in Ahmedabad, gujarat. Nat J Commun Med. 2011;2(2):233-236. 
32. Parray SH, Ahmed D, Ahmed M, Gaash B. Morbidity profile of geriatric population in kashmir. Indian J Practis Doctor. 2008;4(6).

33. Kishore S, Juyal R, Semwal J, Chandra R. Morbidity profile of elderly persons. JK Sci. 2007;9(2):87-89.

34. Mohapatra A, Handoo SK, Gambhir IS, Mohapatra SC. A study of noncommunicable morbidity pattern in geriatric patients attending a referral railway hospital in allahabad, uttar pradesh. Nat J Commun Med. 2011;2 (2):191-195.

35. Srinivasan K, Vaz M, Thomas T. Prevalence of health related disability among community dwelling urban elderly from middle socioeconomic strata in bangaluru, India. Indian J Med Res. 2010;131:515-521.

36. Kakkar R, Aggarwal P, Kandpal SD, Bansal SK. An epidemiological study to assess morbidity profile among geriatric population in district dehradun. Indian J Commun Health. 2013;25(1):39-44.

37. Appels A, Bosma H, Grabauskas V, Gostautas A, Sturmans F. Selfrated health and mortality in a Lithuanian and a Dutch population. Soc Sci Med. 1996;42:681-689.
38. Borawski EA, Kinney JM, Kahana F. The meaning of older adults' health appraisals: congruence with health status and determinant of mortality. $J$ Gerontol B Psychol Sci Soc Sci. 1996;51:S157-170.

39. Chandwani HR, Jivarajani PJ, Jivarajani HP. Health and social problems of geriatric population in an urban setting of gujarat, India. Internet J Health. 2009;9(2)10.5580/d8f.

40. Jadhav VS, Mundada VD, Gaikwad AV, Doibale MK, Kulkani AP. A study of morbidity profile of geriatric population in the field practice area of rural health training centre: paithan of govt medical college, aurangabad. IOSR J Pharm. 2012;2(Mar.-Apr. 2):184-188.

41. Singh AK, Singh M, Singh DS. Health problems in rural elderly at Varanasi, uttar pradesh. J Assoc Physicians India. 1996 Aug;44(8):540-543.

42. Sussman S, Leventhal A, Bluthenthal RN, Freimuth M, Forster M, Ames SL. A framework for the specificity of addictions. Int J Environ Res Public Health. 2011;8:3399-3415.

43. Rahman MO, Barsky AJ. Self-reported health among older Bangladeshis: how good a health indicator is it. Gerontology. 2003;43:856-863. 